\title{
Miglustat Therapy for SCARB2-Associated Action Myoclonus-Renal Failure Syndrome
}

Imran H. Quraishi, MD, PhD, Anna M. Szekely, MD, Anushree C. Shirali, MD, Pramod K. Mistry, MD, PhD, and Lawrence J. Hirsch, MD

Neurol Genet 2021;7:e614. doi:10.1212/NXG.0000000000000614
Correspondence

Dr. Quraishi

imran.quraishi@yale.edu

\section{Abstract}

\section{Objective}

We evaluated whether substrate reduction therapy with miglustat could alter the course of action myoclonus-renal failure syndrome (AMRF), a rare, progressive myoclonic epilepsy with early mortality caused by scavenger receptor class B member 2 (SCARB2) gene mutations.

\section{Methods}

We identified an AMRF patient with a biallelic combination of SCARB2 mutations determined by whole exome sequencing. SCARB2 encodes a protein that traffics $\beta$-glucocerebrosidase to the lysosomal membrane. Mutations lead to a complex pattern of glucosylceramide accumulation and neurologic symptoms including progressive action myoclonus, seizures, and ataxia. We then evaluated the effect of inhibiting glucosylceramide synthesis, as is used in Gaucher disease. The patient was treated for 3 years with miglustat after several years of steady worsening.

\section{Results}

Progression of myoclonus halted, dysphagia resolved, some skills were reacquired, and seizures remained well controlled.

\section{Conclusions}

The response suggests that neurologic symptoms of SCARB2-associated AMRF could be ameliorated, at least partly, by targeting glycosphingolipid metabolism with available medications.

\footnotetext{
From the Yale Comprehensive Epilepsy Center (I.H.Q., L.J.H.), Yale University School of Medicine; Department of Neurology (I.H.Q., A.M.S., L.J.H.), Yale University School of Medicine; Section of Nephrology (A.C.S.), Department of Internal Medicine, Yale University School of Medicine; and Section of Digestive Diseases (P.K.M.), Department of Internal Medicine; Departments of Pediatrics and Cellular and Molecular Physiology, Yale University School of Medicine, New Haven, CT. 


\section{Glossary}

AMRF = action myoclonus-renal failure syndrome; FSGS = focal segmental glomeruloscerosis; GCS = glucosylceramide synthase; GL1 = glucocerebroside; LIMP-2 = lysosomal integral membrane protein type 2; PD = Parkinson disease; SCARB2 = scavenger receptor class B member 2 gene; UPJ = ureteropelvic junction.

Action myoclonus-renal failure syndrome (AMRF) is a rare autosomal recessive progressive myoclonic epilepsy associated with renal disease and caused by scavenger receptor class B member 2 (SCARB2) gene mutations. Symptoms begin in the teens or twenties with tremor, myoclonus, ataxia, and epilepsy, characteristically sparing cognition. ${ }^{1}$ Patients exhibit tremor in the fingers or hands exacerbated by activities such as handwriting, action myoclonus, bulbar myoclonus, and less prominent resting myoclonus of the face, trunk, and limbs. Seizures are often clonic-tonic-clonic. AMRF is relentlessly progressive with a 7- to 15 -year lifespan from symptom onset. ${ }^{2}$ SCARB2 encodes lysosomal integral membrane protein type 2 (LIMP-2), a receptor for $\beta$-glucocerebrosidase (GCase, encoded by the glucosylceramidase beta gene, or GBA), which transports it from the endoplasmic reticulum to lysosomes, where the acidic environment activates its function. SCARB2 mutations lead to impaired GCase trafficking and subsequent toxic accumulation of glucocerebroside (GL1) and its bioactive lipid, glucosylsphingosine. ${ }^{3}$

This glycosphingolipid pathway is also involved in Gaucher disease, in which GBA mutations lead to similar effects (Figure 1C). Substrate reduction therapy targeting GL1 synthesis using glucosylceramide synthase (GCS) inhibitors are accepted therapies for Gaucher disease. The first-generation substrate reduction therapy, miglustat, is approved for mild type 1 Gaucher disease. Eliglustat is the most potent GCS inhibitor but does not cross the blood-brain barrier. Venglustat, a CNS-penetrant GCS inhibitor, is in trials for neuronopathic Gaucher disease and GBA mutationassociated Parkinson disease but was not available (compassionate use declined by the manufacturer). Miglustat exhibits modest CNS penetration and, in addition to Gaucher disease, is approved in Europe for treatment of Niemann-Pick disease type C. Hence, we assessed the response of AMRF to miglustat.

\section{Methods}

We conducted a trial in a patient with this rare, devastating disease that has no approved therapy. Whole exome sequencing was performed by array capture and highthroughput sequencing using an Illumina platform. The mean coverage of the exome was $>100 \times$, and more than $98 \%$ of the exome had at least $20 \times$ coverage. SCARB2 variants in the proband were confirmed by Sanger sequencing. Targeted parental sequencing confirmed the inheritance pattern.

To confirm an effect on lysosomal function, leukocyte $\beta$-glucocerebrosidase activity was measured. We (P.K.M.) designed treatment with a GCS inhibitor (Figure 1C). Miglustat was started at $100 \mathrm{mg}$ twice daily and increased to
$200 \mathrm{mg} 3$ times a day over 6 months to improve brain delivery. This is the upper end of the dose range that has been used and tolerated in trials for Gaucher disease. ${ }^{4}$ Myoclonus was evaluated with video recordings and patient reports. Epilepsy, already well controlled via medications, was evaluated by patient seizure reporting and follow-up EEG.

\section{Standard Protocol Approvals, Registrations, and Patient Consents}

A waiver was obtained from the Yale University Human Investigation Committee (Institutional Review Board Registration \#00011725). The patient provided informed consent for reporting her case.

\section{Data Availability}

Deidentified sequence data will be made available on reasonable request.

\section{Results}

The patient was a 25-year-old lawyer and dancer and presented with seizures and myoclonus. At age 20 years, she developed imbalance and falls with lower extremity jerking. At age 21 years, she developed upper extremity myoclonus and had the first of several bilateral tonic-clonic seizures. At age 22 years, her handwriting started to deteriorate. She developed dysarthria when fatigued. She required a cane at age 23 years and a walker at age 25 years because of lower extremity jerks. Concomitantly, she developed dysphagia. Family history included childhood-onset hearing loss on the maternal side and melanoma on the paternal side, but no seizures or movement disorders (Figure 1A).

Evaluation at age 25 years noted prominent bilateral action myoclonus in her upper more than lower extremities, titubation, wide-based gait, ocular dysmetria, and dysarthria. Mental status, strength, sensation, and reflexes were normal. A video EEG showed sleep-activated, low-amplitude, generalized polyspikes, a myoclonic seizure with a burst of central polyspikes, and innumerable myoclonic jerks without EEG correlates. Brain and spinal MRIs were unrevealing other than mild diffuse atrophy in 2019 compared with that in 2009. Clonazepam had no effect on myoclonus. L-dopa, levetiracetam, and perampanel had mild, transient effects. Valproate had a more sustained effect, but also mild. Clobazam was associated with worsening myoclonus. No medication had a sustained or dramatic response on myoclonus or any effect on progression of other symptoms (Figure 2).

After clinical genetic evaluation, whole exome sequencing revealed 2 pathogenic, biallelic, compound heterozygous 

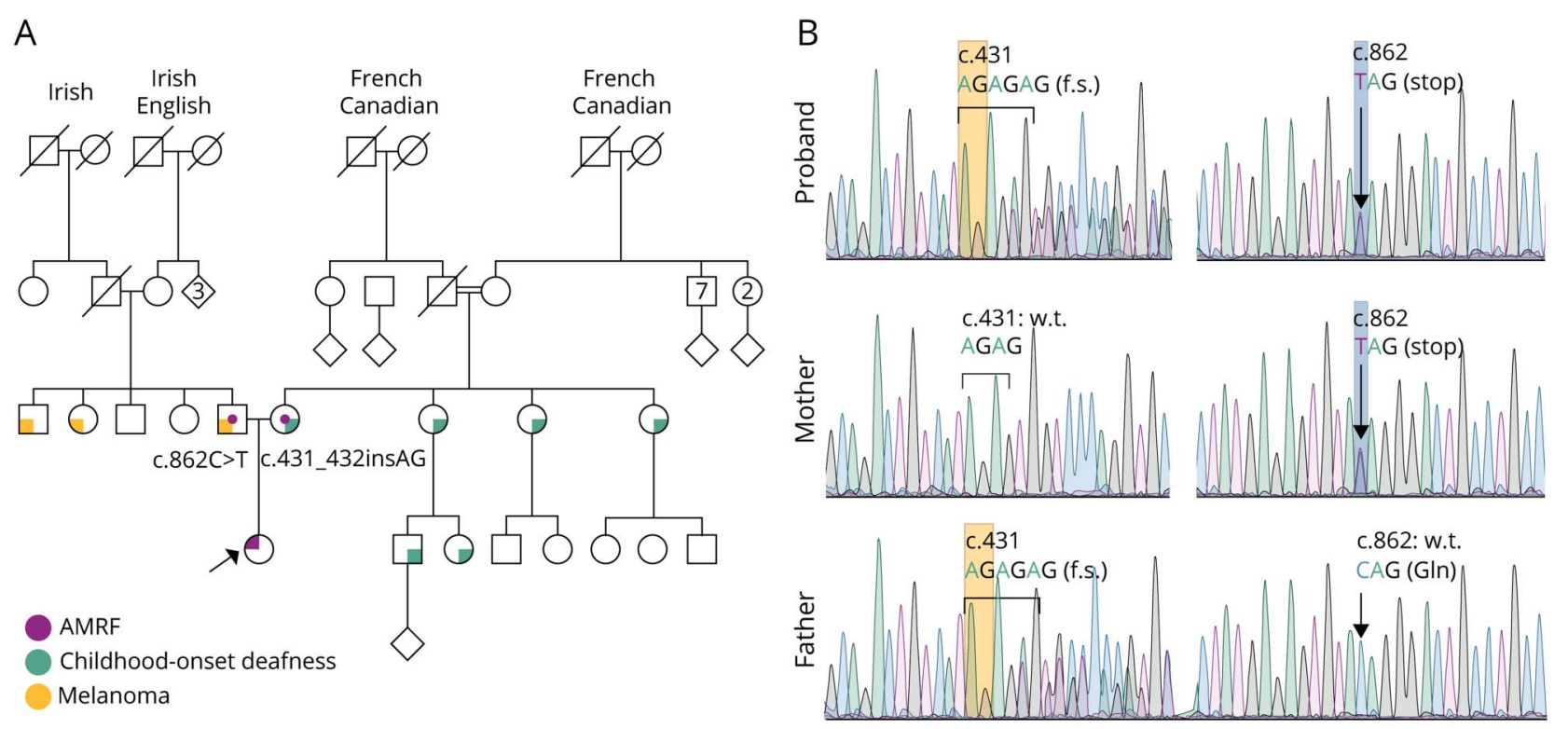

C

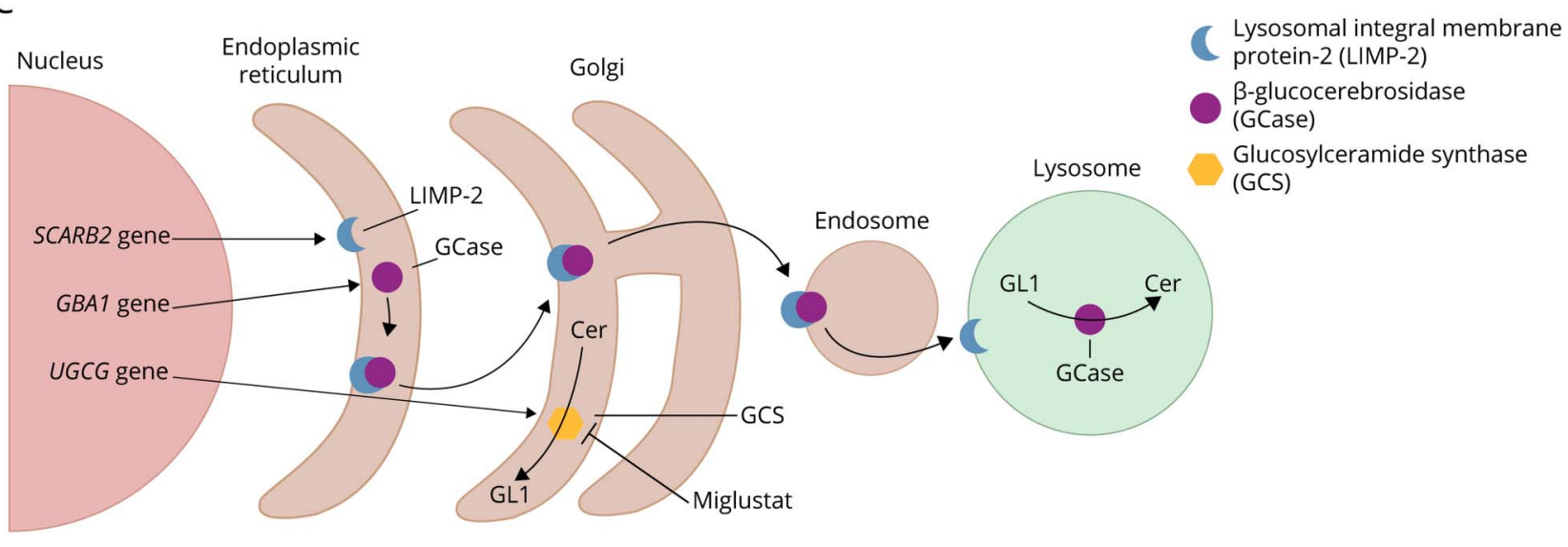

(A) Three-generational pedigree. There is no history of epilepsy or neurologic impairment in the extended family. The mother has isolated childhood-onset hearing loss, similar to her siblings and some of their offspring. The proband's maternal grandparents were first cousins. The father and his siblings have melanoma. The ancestry on the maternal side is French-Canadian and on the paternal side Irish-English. The parent's carrier status is indicated. (B) Sanger sequencing of DNA from the proband and parents showed that the proband inherited the 2 SCARB2 variants independently (w.t. = wild type). A frameshift (f.S.) causing insertion at c.431 was inherited from the mother and is predicted to produce a premature stop codon and truncate the protein to 160 amino acids. A nonsense mutation at c.862 was inherited from the father and is predicted to either truncate the protein product at amino acid 288 or lead to nonsensemediated mRNA decay of the transcript. (C) LIMP-2 binds $\beta$-glucocerebrosidase (GCase, also called $\beta$-glucosidase, and encoded by GBA1) and transports it into lysosomes. GCase normally catalyzes the conversion of lysosomal GL1 (also called glycosylceramide) to ceramide (Cer). Dysfunction of GCase, whether from a GBA1 mutation (Gaucher disease) or from impaired trafficking (SCARB2 mutation, as in AMRF), causes GL1 accumulation. Miglustat antagonizes GL1 synthesis by inhibiting glucosylceramide synthase (also called ceramide glucosyltransferase and encoded by the uridine diphosphate-glucose ceramide glucosyltransferase gene or UGCG), preventing this toxic accumulation.

SCARB2 mutations (Figure 1B). One was an insertion of a dinucleotide repeat, c.431 432insAG on exon 4 (identical to c.435 436insAG), predicted to cause a frameshift and truncate the protein to 160 amino acids (full transcript encodes a 478 amino acid protein). The second, nonsense mutation c.862C > $\mathrm{T}$ (p.Gln288Ter) on exon 7 was predicted to cause loss of function through protein truncation or nonsense-mediated mRNA decay. Parental analysis confirmed that the mutations were independently inherited (Figure 1B). In homozygous cases, they were previously reported in unrelated individuals with AMRF. ${ }^{5}$ No pathogenic GBA variants were identified. Acid $\beta$-glucosidase activity in peripheral blood leukocytes was 7.5 $\mathrm{nmol} / \mathrm{h} / \mathrm{mg}$ protein, which, while lower than normal $(\geq 8.7)$, was not in diagnostic range for Gaucher disease, where enzyme activity is typically less than $10 \%$ of normal value.

With miglustat dose escalation to $200 \mathrm{mg} 3$ times daily, multiple symptoms were ameliorated (Figure 2). Myoclonus and range of motion improved. The patient remained seizure-free. Dysphagia resolved completely; the patient was even able to eat pieces of steak again. EEG 18 months later showed no epileptiform discharges. Coordination and function improved modestly; for example, she was again able to use a joystick to play video games and to use the TV remote. There were no definite side effects. 


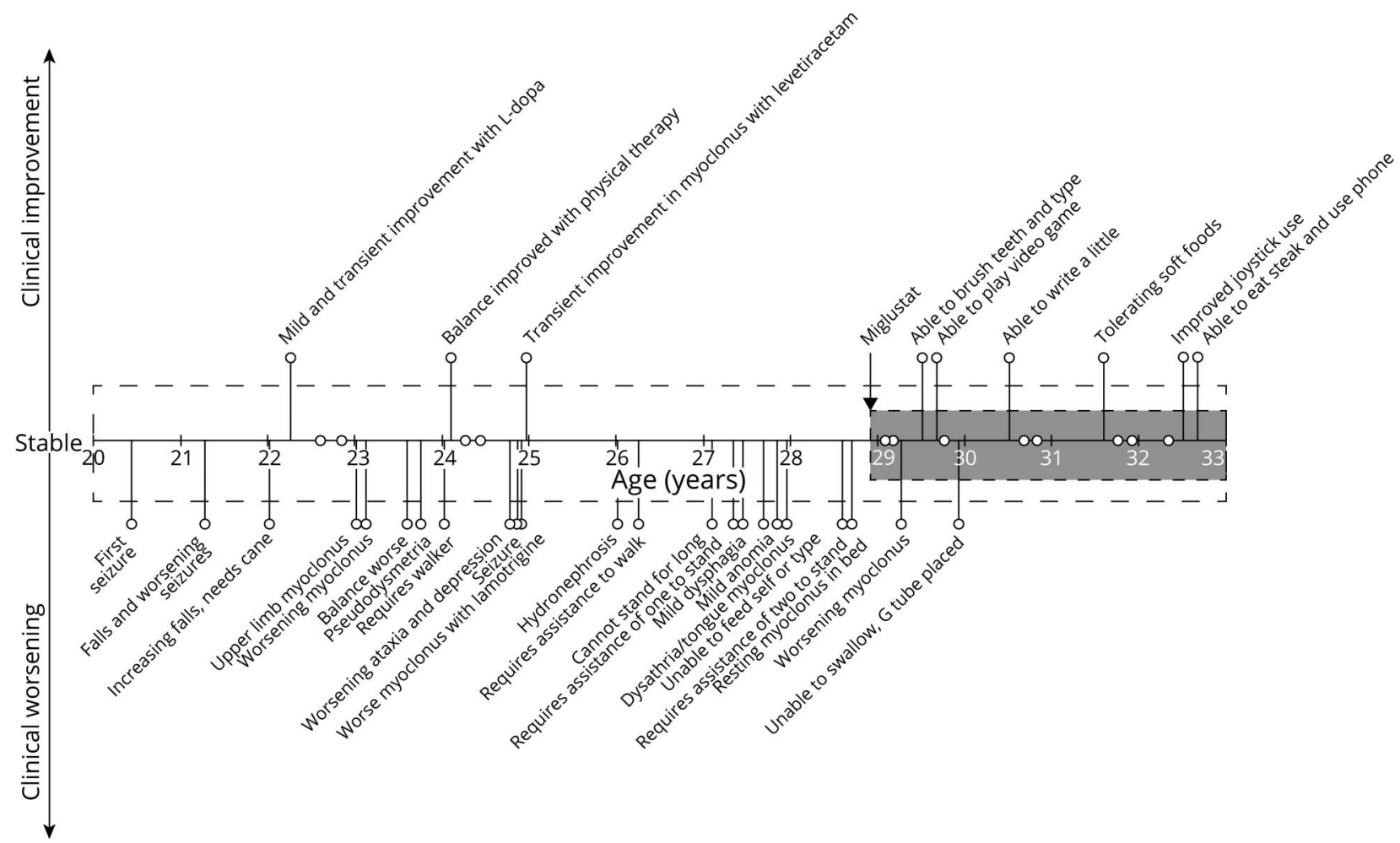

The disease progressed over the first few years from bilateral tonic clonic seizures and falls to worsening action myoclonus and gait to bulbar symptoms. After the initiation of miglustat, starting at $200 \mathrm{mg} / \mathrm{d}$ and titrated up to $600 \mathrm{mg} / \mathrm{d}$, disease progression halted, and the patient regained skills, including the ability to type and use a mobile phone. Each clinic or hospital visit is marked with a circle, with vertical position indicating whether the patient reported new/worsening symptoms (low), improving symptoms (high), or no change (middle).

Although overall improvements were modest, the previously relentless neurologic progression stopped completely.

Renal function was normal with serum creatinine of $0.9 \mathrm{mg} / \mathrm{dL}$ at the time of genetic diagnosis. One year later, she developed right flank pain and hydronephrosis. Creatinine remained at 0.9 $\mathrm{mg} / \mathrm{dL}$, but proteinuria measured by spot urine testing was at 1.9 $\mathrm{g} / \mathrm{g}$ creatinine. CT and retrograde pyelogram demonstrated a unilateral ureteropelvic junction (UPJ) obstruction from suspected congenital stricture. The obstruction was corrected with a stent, followed by pyeloplasty. Intraoperative renal biopsy (at age 26 years) showed early reflux nephropathy, but no evidence of glomerulosclerosis on light microscopy or podocyte effacement on electron microscopy. Over the next few years, she developed progressive renal insufficiency with creatinine rising to $1.42 \mathrm{mg} /$ $\mathrm{dL}$, but proteinuria declined to $0.23 \mathrm{~g} / \mathrm{g}$ creatinine.

\section{Discussion}

We described a patient with AMRF due to biallelic SCARB2 mutations with predicted loss of protein function. While these variants were previously identified in homozygous state in patients with $\mathrm{AMRF},{ }^{5}$ compound heterozygosity has not been described. The patient had prominent action myoclonus, controlled epilepsy, and dysphagia. Childhood-onset hearing loss in the maternal family was suspected to represent a separate entity of hereditary nonsyndromic deafness. Because SCARB2 mutations lead to GCase dysfunction and the patient was deteriorating rapidly, we assessed a trial of treatment with miglustat. Treatment resulted in arrest of progression of myoclonus, resolution of dysphagia, and mild overall sustained improvement over 3 years.

Treatment of AMRF with miglustat was described previously in 1 patient in $2011 .^{6}$ In that report, 1 of the 2 siblings with AMRF (with homozygous SCARB2 variants introducing premature stop codon p.Trp178Ter) ${ }^{7}$ was treated with miglustat $600 \mathrm{mg} / \mathrm{d}$ for 2 years starting at age 24 years, after earlier GCase enzyme replacement therapy with no improvement for 1 year. The patient's age at onset and presentation, apart from the renal features, were similar to the patient we have presented, including an EEG showing generalized discharges, antiseizure medications yielding only transient benefit, instability due to myoclonic jerks, and requirement for nasogastric tube. Similar to our patient, myoclonus improved and dysphagia resolved; however, that patient died of pneumonia at age 26 years.

Myoclonus and seizures in AMRF progress independently of renal failure. ${ }^{8}$ Usually, renal manifestations include proteinuria, which may be nephrotic, with histology revealing 
interstitial fibrosis, atrophy, and focal segmental glomeruloscerosis (FSGS). However, some cases with certain biallelic SCARB2 variants have been described as not having progressive renal failure from FSGS. ${ }^{9}$ In our patient, kidney biopsy showed no evidence of FSGS (not repeated since). Subsequently, creatinine has progressively but slowly increased without concomitant rise in proteinuria, as is more typical of progressive renal failure from FSGS, including cases of FSGS in AMRF. It is unknown whether the renal phenotype was slowed by the miglustat treatment or whether her AMRF represents a variant $S C A R B 2$ mutation with milder kidney disease.

In addition, this patient had an anatomical UPJ obstruction, likely congenital, which was corrected surgically. She has not shown evidence of recurrent obstruction. However, the patient's kidney biopsy indicated fibrosis in a striped pattern, which can be seen in obstructive nephropathy. Thus, her slowly progressive loss of kidney function may be more consistent with chronic obstructive nephropathy. UPJ obstruction has not been reported in patients with AMRF, ${ }^{5}$ including the previously reported patient who was treated with miglustat and had different renal pathology than our patient. ${ }^{6}$ It is, however, seen in $\operatorname{Limp} 2^{-/-}$mice, which develop hydronephrosis due to UPJ obstruction and proteinuria with glomerular foot-process effacement, but not FSGS. $^{10}$

The lysosomal pathway targeted in this case is important in other neurologic disorders. Human Parkinson disease (PD) brains have reduced GCase activity in substantia nigra. ${ }^{11}$ GBA mutations are a risk factor of $\mathrm{PD}$, and genome-wide association studies suggest that $S C A R B 2$ variants may also increase PD risk. ${ }^{12}$ Miglustat is a weak GCS inhibitor; a higher potency alternative with better brain penetrance, venglustat, is now in trials for GBA mutation-associated PD and neuronopathic Gaucher disease. $^{13,14}$

Although this is a single case, it provides confirmation to a prior case report of miglustat responsiveness from 10 years ago, ${ }^{6}$ and because AMRF is relentlessly progressive with no other available therapies, consideration should be given to miglustat or related medications in patients with mutations in SCARB2 and conceivably other genes associated with impaired lysosomal metabolism. Our report is limited by subjectivity in reporting of myoclonus, dysphagia, and other symptoms. Future, larger, prospective trials should incorporate standardized scales for myoclonus and other symptoms. However, this therapy has the potential to be disease modifying, and we hope this report will encourage it to be tried early in the disease course as we gather additional evidence.

\section{Acknowledgment}

The authors thank the patient and her family for their participation as well as the Yale University DNA Diagnostics Laboratory.

\section{Study Funding}

The authors report no targeted funding.

\section{Disclosure}

The authors report no disclosures relevant to the manuscript. Go to Neurology.org/NG for full disclosures.

\section{Publication History}

Received by Neurology: Genetics March 2, 2021. Accepted in final form June 11, 2021.

\section{Appendix Authors}

\begin{tabular}{lll}
\hline Name & Location & Contribution \\
\hline Imran H. & Yale Comprehensive Epilepsy & Drafting/revision of the \\
Quraishi, & $\begin{array}{l}\text { Center, Yale University School } \\
\text { of Medicine; Department of } \\
\text { MD, PhD } \\
\text { Neurology, Yale University } \\
\text { School of Medicine, New } \\
\text { Haven, CT }\end{array}$ & $\begin{array}{l}\text { including medical writing } \\
\text { for content; } \text { major role in } \\
\text { the acquisition of data; } \\
\text { analysis or interpretation of } \\
\text { data }\end{array}$ \\
\hline
\end{tabular}

Anna M. Department of Neurology, Yale Drafting/revision of the Szekely, University School of Medicine, manuscript for content, MD New Haven, CT including medical writing for content; major role in the acquisition of data; analysis or interpretation of data

\begin{tabular}{|c|c|c|}
\hline $\begin{array}{l}\text { Anushree } \\
\text { C. Shirali, } \\
\text { MD }\end{array}$ & $\begin{array}{l}\text { Section of Nephrology, } \\
\text { Department of Internal } \\
\text { Medicine, Yale University } \\
\text { School of Medicine, New } \\
\text { Haven, CT }\end{array}$ & $\begin{array}{l}\text { Drafting/revision of the } \\
\text { manuscript for content, } \\
\text { including medical writing } \\
\text { for content; major role in } \\
\text { the acquisition of data; } \\
\text { analysis or interpretation of } \\
\text { data }\end{array}$ \\
\hline
\end{tabular}

Pramod K. Section of Digestive diseases, Mistry, MD, Department of Internal PhD Medicine; Departments of Pediatrics and Cellular and Molecular Physiology, Yale University School of Medicine, New Haven, CT

Drafting/revision of the manuscript for content, including medical writing for content; major role in the acquisition of data; study concept or design; analysis or interpretation of data

Lawrence J. Yale Comprehensive Epilepsy Hirsch, MD Center, Yale University School of Medicine; Department of Neurology, Yale University School of Medicine, New Haven, CT

Drafting/revision of the manuscript for content, including medical writing for content; major role in the acquisition of data; study concept or design; analysis or interpretation of data

\section{References}

1. Dibbens L, Schwake M, Saftig P, Rubboli G. SCARB2/LIMP2 deficiency in action myoclonus-renal failure syndrome. Epileptic Disord. 2016;18(S2):63-72.

2. Amrom D, Andermann F, Andermann E. Action myoclonus-renal failure syndrome. In: Adam M, Ardinger H, Pagon R, et al, eds. GeneReviews. University of Washington; 2015.

3. Blanz J, Groth J, Zachos C, Wehling C, Saftig P, Schwake M. Disease-causing mutations within the lysosomal integral membrane protein type 2 (LIMP-2) reveal the nature of binding to its ligand beta-glucocerebrosidase. Hum Mol Genet. 2010;19(4): 563-572.

4. Schiffmann R, Fitzgibbon EJ, Harris C, et al. Randomized, controlled trial of miglustat in Gaucher's disease type 3. Ann Neurol. 2008;64(5):514-522. 
5. Berkovic SF, Dibbens LM, Oshlack A, et al. Array-based gene discovery with three unrelated subjects shows SCARB2/LIMP-2 deficiency causes myoclonus epilepsy and glomerulosclerosis. Am J Hum Genet. 2008;82(3):673-684.

6. Chaves J, Beirão I, Balreira A, et al. Progressive myoclonus epilepsy with nephropathy C1q due to SCARB2/LIMP-2 deficiency: clinical report of two siblings. Seizure. 2011; 20(9):738-40.

7. Balreira A, Gaspar P, Caiola D, et al. A nonsense mutation in the LIMP-2 gene associated with progressive myoclonic epilepsy and nephrotic syndrome. Hum Mol Genet. 2008;17(14):2238-2243.

8. Badhwar A, Berkovic SF, Dowling JP, et al. Action myoclonus-renal failure syndrome: characterization of a unique cerebro-renal disorder. Brain. 2004;127(10):2173-2182.

9. Dibbens LM, Michelucci R, Gambardella A, et al. SCARB2 mutations in progressive myoclonus epilepsy (PME) without renal failure. Ann Neurol. 2009;66(4):532-536.
10. Gamp AC, Tanaka Y, Lüllmann-Rauch R, et al. LIMP-2/LGP85 deficiency causes ureteric pelvic junction obstruction, deafness and peripheral neuropathy in mice. Hum Mol Genet. 2003;12(6):631-646.

11. Gegg ME, Burke D, Heales SJ, et al. Glucocerebrosidase deficiency in substantia nigra of Parkinson disease brains. Ann Neurol. 2012;72(3):455-463.

12. Bellomo G, Paciotti S, Gatticchi L, Parnetti L. The vicious cycle between $\alpha$-synuclein aggregation and autophagic-lysosomal dysfunction. Mov Disord. 2020;35(1):34-44.

13. Peterschmitt MJ, Saiki H, Hatano T, et al. Safety, pharmacokinetics, and pharmacodynamics of oral venglustat in Parkinson disease patients with a GBA mutation from Japan and the rest of the world: results from part 1 of the MOVES-PD study. Mol Genet Metab. 2020;129:S128.

14. Do J, McKinney C, Sharma P, Sidransky E. Glucocerebrosidase and its relevance to Parkinson disease. Mol Neurodegener. 2019;14(1):36. 


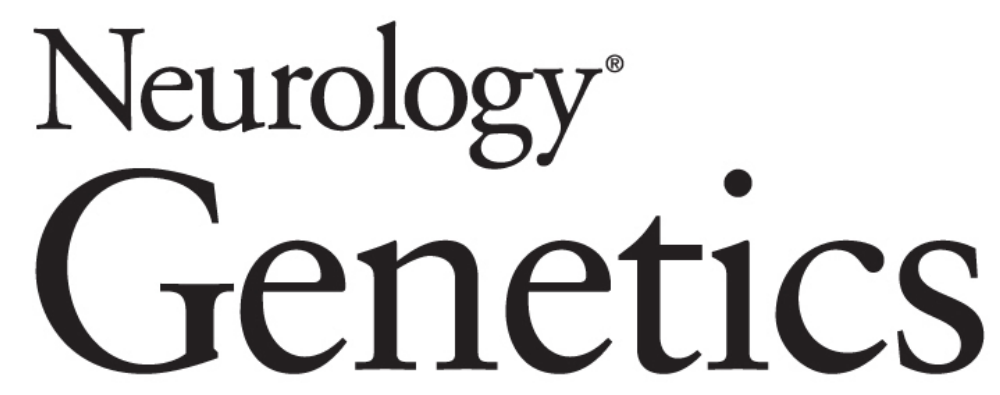

\section{Miglustat Therapy for SCARB2-Associated Action Myoclonus-Renal Failure Syndrome}

Imran H. Quraishi, Anna M. Szekely, Anushree C. Shirali, et al. Neurol Genet 2021;7;

DOI 10.1212/NXG.0000000000000614

This information is current as of July 28, 2021

\section{Updated Information \&} Services

References

Permissions \& Licensing

Reprints including high resolution figures, can be found at: http://ng.neurology.org/content/7/5/e614.full.html

This article cites 13 articles, 0 of which you can access for free at: http://ng.neurology.org/content/7/5/e614.full.html\#\#ref-list-1

Information about reproducing this article in parts (figures,tables) or in its entirety can be found online at:

http://ng.neurology.org/misc/about.xhtml\#permissions

Information about ordering reprints can be found online: http://ng.neurology.org/misc/addir.xhtml\#reprintsus

Neurol Genet is an official journal of the American Academy of Neurology. Published since April 2015, it is an open-access, online-only, continuous publication journal. Copyright Copyright (C) 2021 The Author(s). Published by Wolters Kluwer Health, Inc. on behalf of the American Academy of Neurology.. All rights reserved. Online ISSN: 2376-7839.

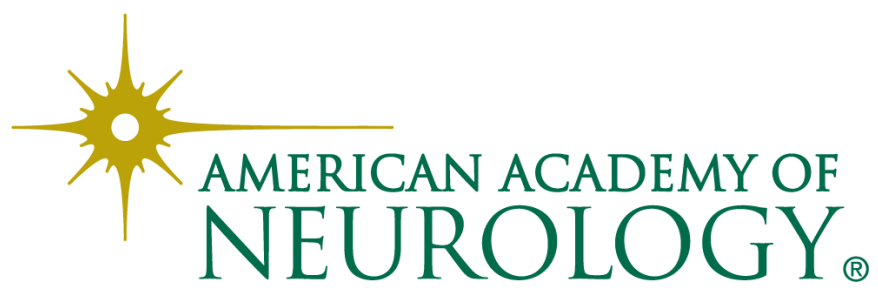

